\title{
A Turbine-Driven Ventilator Improves Adherence to Advanced Cardiac Life Support Guidelines During a Cardiopulmonary Resuscitation Simulation
}

\author{
Scott G Allen MD RRT, Lara Brewer PhD, Erik S Gillis, Nathan L Pace MD MStat, \\ Derek J Sakata MD, and Joseph A Orr PhD
}

\begin{abstract}
BACKGROUND: Research has shown that increased breathing frequency during cardiopulmonary resuscitation is inversely correlated with systolic blood pressure. Rescuers often hyperventilate during cardiopulmonary resuscitation (CPR). Current American Heart Association advanced cardiac life support recommends a ventilation rate of 8-10 breaths/min. We hypothesized that a small, turbine-driven ventilator would allow rescuers to adhere more closely to advanced cardiac life support (ACLS) guidelines. METHODS: Twenty-four ACLS-certified health-care professionals were paired into groups of 2. Each team performed 4 randomized rounds of 2-min cycles of CPR on an intubated mannikin, with individuals altering between compressions and breaths. Two rounds of CPR were performed with a self-inflating bag, and 2 rounds were with the ventilator. The ventilator was set to deliver 8 breaths/min, pressure limit $22 \mathrm{~cm} \mathrm{H}_{2} \mathrm{O}$. Frequency, tidal volume $\left(\mathrm{V}_{T}\right)$, peak inspiratory pressure, and compression interruptions (hands-off time) were recorded. Data were analyzed with a linear mixed model and Welch 2-sample $t$ test. RESULTS: The median (interquartile range [IQR]) frequency with the ventilator was $7.98(7.98-7.99)$ breaths $/ \mathrm{min}$. Median (IQR) frequency with the self-inflating bag was $9.5(8.2-10.7)$ breaths $/ \mathrm{min}$. Median (IQR) ventilator $\mathrm{V}_{\mathrm{T}}$ was $0.5(0.5-0.5) \mathrm{L}$. Median (IQR) self-inflating bag $\mathrm{V}_{\mathrm{T}}$ was $0.6(0.5-0.7) \mathrm{L}$. Median (IQR) ventilator peak inspiratory pressure was $22(22-22) \mathrm{cm} \mathrm{H}_{2} \mathrm{O}$. Median (IQR) self-inflating bag peak inspiratory pressure was $30(27-35) \mathrm{cm} \mathrm{H}_{2} \mathrm{O}$. Mean \pm SD hands-off times for ventilator and selfinflating bag were $5.25 \pm 2.11$ and $6.41 \pm 1.45 \mathrm{~s}$, respectively. CONCLUSIONS: When compared with a ventilator, volunteers ventilated with a self-inflating bag within ACLS guidelines. However, volunteers ventilated with increased variation, at higher $V_{T}$ levels, and at higher peak pressures with the self-inflating bag. Hands-off time was also significantly lower with the ventilator. (ClinicalTrials.gov registration NCT02743299.) Key words: ventilator; resuscitation; simulation training; equipment and supplies. [Respir Care 2017;62(9):1166-1170. ㅇ 2017 Daedalus Enterprises]
\end{abstract}

\section{Introduction}

Studies suggest that hyperventilation during cardiopulmonary resuscitation (CPR) is inversely correlated with

\footnotetext{
Drs Allen, Brewer, Pace, and Orr are affiliated with the Department of Anesthesiology, University of Utah, Salt Lake City, Utah. Dr Sakata is affiliated with the Department of Anesthesiology, University of Utah. Mr Gillis is affiliated with the Physician Assistant School at Duke University, Durham, North Carolina.
}

Dr Sakata has disclosed relationships with Axon Medical, MedVis, Anecare, and Dynasthetics. Dr Orr has disclosed relationships with Axon systolic blood pressure during CPR. ${ }^{1}$ Positive-pressure ventilation increases intrathoracic pressure, which in turn impedes venous return to the heart. During low-flow states such as CPR, this inverse correlation is exacerbated. ${ }^{2}$ This has been shown in several animal studies and one obser-

\footnotetext{
Medical, Dynasthetics, Korr Medical Technologies, Philips, and Anecare. The other authors have disclosed no conflicts of interest. The device being investigated was developed by the Bioengineering Division of the Department of Anesthesiology at the University of Utah. Any intellectual property for this device has been assigned to the University of Utah. Further, the University of Utah has not licensed any of the rights for this device to Drs Orr or Sakata or to any of their owned entities.
} 
Table 1. Participant Role by Education and Training

\begin{tabular}{lc}
\hline \hline \multicolumn{1}{c}{ Participant Role } & Number of Participants \\
\hline Anesthesiology attending & 3 \\
Anesthesiology resident & 9 \\
Anesthesiology technician & 3 \\
Registered nurse & 6 \\
Respiratory therapist & 2 \\
Medical student & 1 \\
\hline
\end{tabular}

vational study in humans. ${ }^{3,4}$ Ventilation during CPR can be performed by bag-mask ventilation or an advanced airway (endotracheal tube or supraglottic airway). Current evidence does not support the superiority of ventilating via an advanced airway or bag-mask, in terms of neurological outcome or survival to hospital discharge. The choice is therefore left to the skilled provider. ${ }^{5,6}$ In light of recent research into the risks of hyperventilation during CPR, the American Heart Association has updated the 2015 advanced cardiac life support (ACLS) guidelines to recommend that 1 breath every $6 \mathrm{~s}$ (10 breaths/min) be delivered while continuous chest compressions are being performed. In the absence of an advanced airway, a 30:2 compression/ventilation ratio is recommended, with pauses in compressions for breath delivery. ${ }^{7}$ Despite these recommendations and certification every $2 \mathrm{y}$, rescuers exceed the recommended ventilation rate in up to $63 \%$ of resuscitations. $^{2}$

In addition to avoiding excessive ventilation, the other critical components of high-quality CPR are minimizing interruptions in chest compressions (hands-off time), providing compressions of adequate rate and depth, and avoiding leaning between compressions. ${ }^{8}{ }^{89}$ In the 2015 ACLS guidelines, optimizing coronary perfusion pressure, $\geq 15 \mathrm{~mm} \mathrm{Hg}$, is mentioned as a critical factor for the return of spontaneous circulation. Further, according to the ACLS guidelines, minimizing interruptions in chest compressions correlates with maintaining a more adequate coronary perfusion pressure.

A small, turbine-driven ventilator that does not require a compressed gas source is in development. Because hyperventilation is so common during resuscitation, the authors hypothesized that this portable ventilator would allow rescuers to adhere more closely to ACLS ventilation

Dr Allen presented a version of this work at the International Anesthesia Research Society Meeting, held May 17, 2014, in Montreal, Canada.

Correspondence: Scott Allen MD RRT, University of Utah, 50 North Medical Drive, Salt Lake City, UT 84132. E-mail: scott.allen@hsc.utah.edu.

DOI: $10.4187 /$ respcare. 05368

\section{QUICK LOOK}

\section{Current knowledge}

Excessive ventilations are inversely correlated with blood pressure during cardiopulmonary resuscitation (CPR). Current advanced cardiac life support guidelines recommend $8-10$ breaths $/ \mathrm{min}$. Providers often perform excessive ventilations during CPR.

\section{What this paper contributes to our knowledge}

In a simulated CPR session, volunteers gave consistent tidal volumes, peak pressures, and breathing frequencies with a ventilator when compared with a self-inflating bag, adhering more closely to advanced cardiac life support guidelines and decreasing hands-off time. Volunteers provided low breathing frequencies with the bag, but the results were widely variable. This has implications for code teams, ambulances, and military medicine.

guidelines and provide more of the critical elements of high-quality CPR.

\section{Methods}

After obtaining institutional review board approval from the University of Utah, 24 ACLS professionals were recruited for the study. Informed consent was obtained from each participant. The participants were then placed in groups of 2. The clinical background of each participant is shown in Table 1. The teams were then briefed on the CPR protocol.

For the CPR protocol, the rescuers were brought to a research laboratory that contained an intubated SimMan $3 \mathrm{G}$ mannikin (Laerdal, Stavanger, Norway) on a table. To simulate clinical practice, no coaching about CPR guidelines was given to the participants. The rescuers were told the aim of the study was to "improve adherence to ACLS guidelines." There were no handouts or discussions of ACLS guidelines before the start of the simulation. They were not told about the hypothesis of the study. They were allowed to cross-talk with each other if they had questions about ventilation and compression ratios. A brief tutorial was given on how to use the ventilator, which consisted of connecting the ventilator tubing to the endotracheal tube and turning it on. The ventilator was set to deliver 8 breaths/min at $22 \mathrm{~cm} \mathrm{H}_{2} \mathrm{O}$. All participants were already familiar with use of the self-inflating bag (Ambubag, AMBU, Glen Burnie, Maryland).

Each team performed 4 rounds of CPR on the intubated mannikin, consisting of 2-min cycles. Two rounds were 
with the ventilator, and 2 rounds were with the self-inflating bag. Individuals alternated between compressions and ventilations. The order of starting the first round with the self-inflating bag or ventilator was randomized to avoid performance bias. An observer simulated a CPR scenario and told the participants when to start and when to switch positions.

Hands-off time was defined as the amount of time that rescuers were not actively performing compressions. Because the mannikin was intubated, compressions and ventilations were not synchronized. In this scenario, hands-off time was the time it took for rescuers to change positions from compressions to ventilations.

\section{Data Acquisition}

The SimMan 3G (Laerdal, Stavanger, Norway) mannikin was equipped with an artificial lung that collected respiratory parameters. Tidal volume $\left(\mathrm{V}_{\mathrm{T}}\right)$, breathing frequency, and peak airway pressures were collected automatically with the NM3 module (Phillips Medical, Wallingford, Connecticut). Compression interruptions (hands-off time) were recorded by the observer. Due to limitations of the mannikin, the test lung that collected data was located outside the mannikin, covered by a box to avoid bias in participants. This allowed participants to perform compressions while allowing accurate measurement of respiratory parameters.

\section{Statistical Analysis}

Simple descriptive statistics included means \pm SD values and medians with interquartile range (IQR). Because there were unequal variances by type of ventilation for breathing frequency, $\mathrm{V}_{\mathrm{T}}$, and peak inspiratory pressure, these are reported as medians (IQR). Differences for variables by type of ventilation were estimated by linear mixedeffects quantile regression with a random intercept for each team. Hands-off times were compared by a paired $t$ test.

Statistical models and plots were estimated and created in the R 3.2.4 environment (R Foundation for Statistical Computing, Vienna, Austria). Packages used included lme4 $1.1-11^{10}$, lmerTest $2.0-30^{11}$, lqmm $1.5 .3^{12}$, and ggplot2 2.1.013.

\section{Results}

Twelve pairs of volunteers performing 4 rounds of CPR were analyzed (see Table 1). The median (IQR) frequency with the ventilator was 7.98 (7.98-7.99) breaths/min. Median (IQR) frequency with the self-inflating bag was 9.5 (8.2-10.7) breaths/min. For the self-inflating bag, the median frequency was 1.4 breaths/min ( $95 \%$ CI -0.3 to

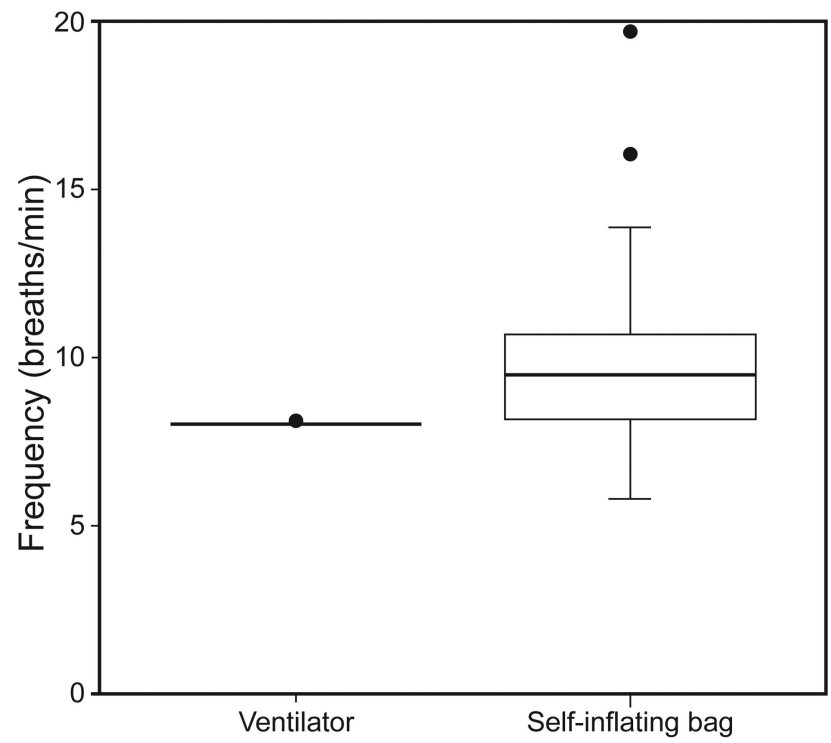

Fig. 1. Breathing frequency during cardiopulmonary resuscitation simulation. Center lines represent median, and boxes show interquartile range. Whiskers denote all data points within 1.5 interquartile ranges. Dots are outliers. Because ventilator frequency is fixed, there was no variation.

3 breaths/min) higher, but this was not a statistically significant difference $(P=.11)$ (Fig. 1). Median (IQR) ventilator $\mathrm{V}_{\mathrm{T}}$ was $0.5(0.5-0.5) \mathrm{L}$. Median (IQR) self-inflating bag $\mathrm{V}_{\mathrm{T}}$ was $0.6(0.5-0.7) \mathrm{L}$. The median $\mathrm{V}_{\mathrm{T}}$ was $0.1 \mathrm{~L}$ (95\% CI $0.03-0.2 \mathrm{~L})$ higher $(P=.007)$ for self-inflating bag ventilation (Fig. 2). Median (IQR) ventilator peak inspiratory pressure was $22(22-22) \mathrm{cm} \mathrm{H}_{2} \mathrm{O}$. Median (IQR) self-inflating bag peak inspiratory pressure was $30(2-35) \mathrm{cm} \mathrm{H}_{2} \mathrm{O}$. The median pressure was $8 \mathrm{~cm} \mathrm{H}_{2} \mathrm{O}$ (95\% CI 3-12 $\left.\mathrm{cm} \mathrm{H}_{2} \mathrm{O}\right)$ higher $(P<.001)$ for selfinflating bag ventilation (Fig. 3). Mean \pm SD hands-off time for ventilator and self-inflating bag were $5.25 \pm 2.11$ and $6.41 \pm 1.45 \mathrm{~s}$, respectively. This difference was statistically significant $(1.2 \mathrm{~s}, 95 \%$ CI $0.7-$ 1.6, $P<.001)$.

\section{Discussion}

The data collected in this study show that, in a simulated CPR model, rescuers can follow ACLS guidelines more closely when using an automated ventilator. The ventilator allows rescuers to provide consistent $\mathrm{V}_{\mathrm{T}}$ levels, frequency, and peak pressures. Previous studies have shown that rescuers often hyperventilate patients during CPR. ${ }^{2,3}$ In our simulated study, participants did not deliver excessively high frequencies when using a self-inflating bag on the CPR mannikin. This was without the aid of a metronome or timer to assist the participant. However, inter-performer variability was high. When using the self-inflating bag, participants ventilated at a 


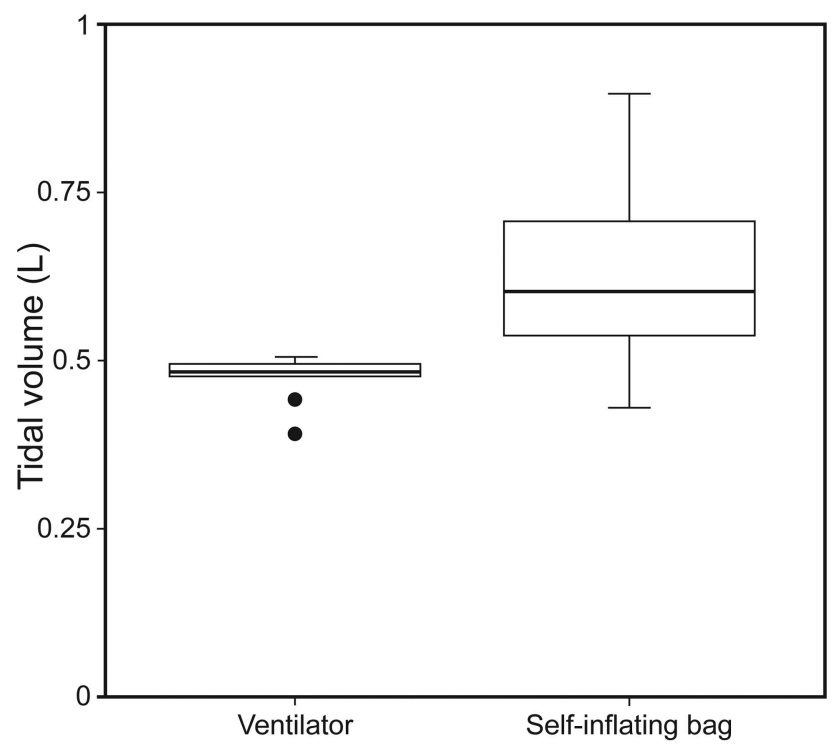

Fig. 2. Tidal volume during cardiopulmonary resuscitation simulation. Center lines represent median, and boxes show interquartile range. Whiskers denote all data points within 1.5 interquartile ranges. Dots are outliers.

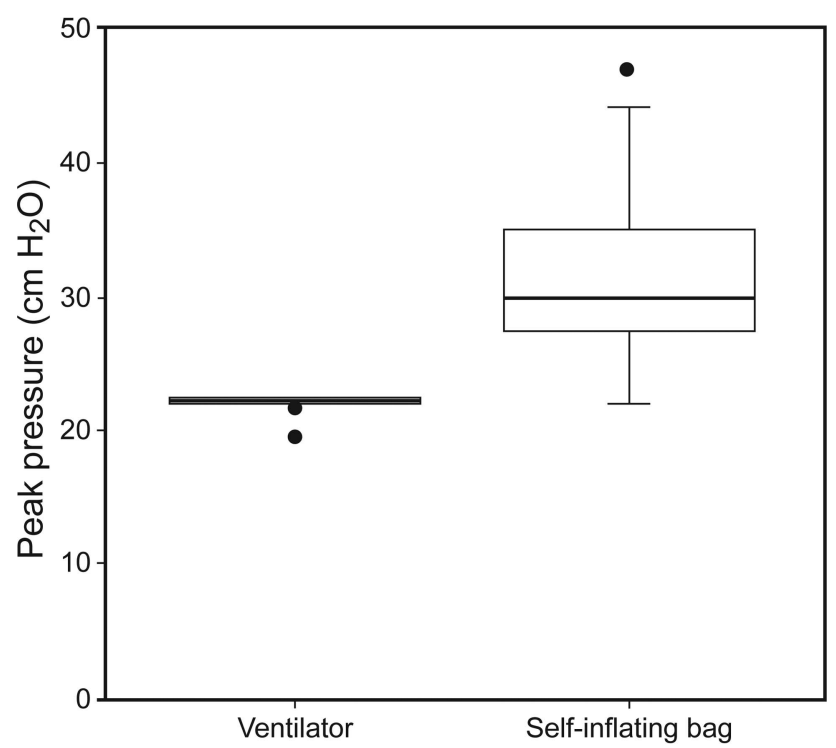

Fig. 3. Peak pressure during cardiopulmonary resuscitation simulation. Center lines represent median, and boxes show interquartile range. Whiskers denote all data points within 1.5 interquartile ranges. Dots are outliers.

significantly higher $\mathrm{V}_{\mathrm{T}}$ and peak pressures, with high variability among participants. This variability when using the self-inflating bag is consistent with previous research. ${ }^{14}$ As was mentioned previously, higher airway pressures can increase intrathoracic pressure and decrease venous return.

Our results also show that rescuers had a significantly lower mean hands-off time during this CPR simulation.

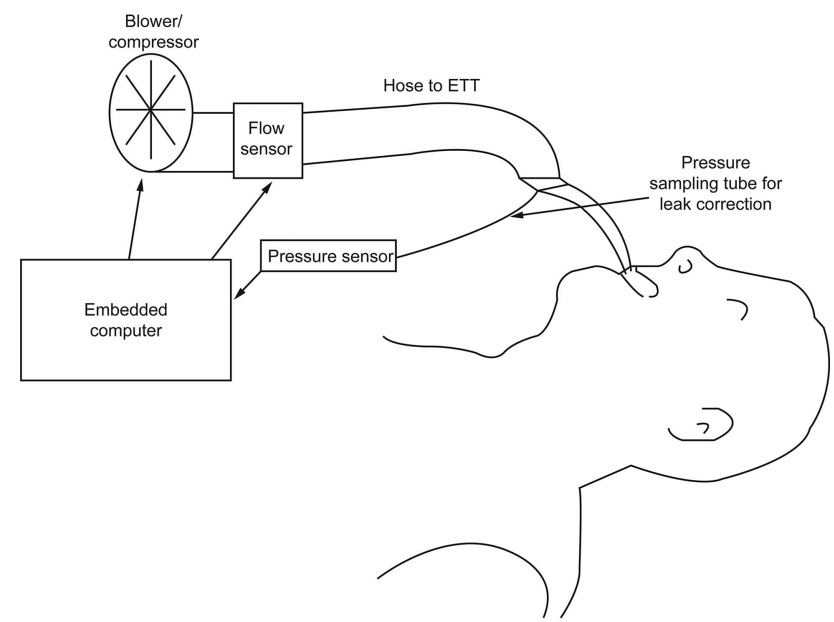

Fig. 4. Schematic of the ventilator. The flow sensor and embedded computer allow for tube leak compensation.

Hands-off time correlates with more compressions and more forward blood flow during resuscitation. Because the mannikin was intubated and the breaths were not synchronized with compressions, it is likely that the reduction in hands-off time came from not having to manipulate the self-inflating bag during the ventilator scenario. The use of a ventilator during CPR has been shown to decrease the hands-off time of inexperienced providers. ${ }^{14,15}$ To our knowledge, this is the first study to show that a ventilator can decrease hands-off time for providers with significant resuscitation experience.

The use of a turbine-powered ventilator, as opposed to a pneumatic one, is significant because turbine ventilators have been shown to have lower $\mathrm{V}_{\mathrm{T}}$ variability in bench studies. ${ }^{16}$ Turbine ventilators can provide an $\mathrm{F}_{\mathrm{IO}_{2}}$ of .90 when coupled with an oxygen concentrator. ${ }^{17}$ This has implications in low-resource settings, such as ambulances, crash carts, developing countries, or battlefield hospitals. This handheld ventilator is novel because it is specifically designed for use during emergency ventilation. The ventilator is designed to be more reliable and easy to use than the traditional self-inflating bag. It weighs $1.4 \mathrm{~kg}$ (a commercial version could weigh half as much) and is designed to provide positive-pressure breaths only when it detects that a mask is on the patient. Other blower-based ventilators on the market are larger and are designed to provide ventilation for a patient in a stable environment, such as the ICU. A schematic of the ventilator is shown in Figure 4.

One advantage of a blower-based positive-pressure breath over the traditional self-inflating bag is that it has the capacity to compensate for a leak, whether through a mask or endotracheal tube, thus preserving delivered $\mathrm{V}_{\mathrm{T}}$. A second advantage of a blower-based positive-pressure ventilator is that pressure safety limits are programmed into the ventilator. With a traditional self-inflating bag, in 
comparison, it is possible to go beyond safe pressure limits when delivering a manual breath to the patient. The advantages provided by a blower are not necessarily unique to this device. If clinicians decide to use ventilators for CPR, any portable ventilator would probably improve guideline adherence.

\section{Limitations}

There are several limitations to this study. It was a simulated CPR study on a mannikin and was not performed on humans. The peak pressure and $\mathrm{V}_{\mathrm{T}}$ data would probably change when measured in real-life situations with lungs inside a body. However, the frequency delivered by the ventilator would not change. The study was performed in a controlled laboratory setting, rather than in an ambulance or emergency department. This allowed volunteers to use the self-inflating bag in nearly ideal conditions. The observed high variability of the self-inflating bag would probably be even higher in the field. In our study, $60 \%$ of rescuers were anesthesiologists or anesthesia residents. This is not typical of most code situations, which are run by nurses and respiratory therapists. A similar study could be performed to more accurately reflect the real-life makeup of code teams.

Ventilations were not synchronized with the relaxation phase of chest compressions, and the test lung was located outside of the mannikin. Were this study to be repeated in humans, this coordination of compressions and ventilations to maximize ventilation efficiency would be of great value. In the absence of coordination, there may be a variation in $\mathrm{V}_{\mathrm{T}}$.

\section{Conclusions}

A small turbine-driven ventilator allows rescuers to adhere more closely to ACLS guidelines in a simulated CPR scenario. This ventilator also has the advantage of not requiring a compressed gas source, allowing it to be used in low-resource areas, such as ambulances, the battlefield or developing countries. It could be placed in a crash cart in hospitals. By delivering ventilations with less variation, lower $\mathrm{V}_{\mathrm{T}}$ levels, and lower peak pressures than the selfinflating bag, this ventilator could improve cardiac output during CPR. The use of a ventilator during CPR simulation has also been shown to decrease hands-off time in experienced providers.

\section{REFERENCES}

1. Aufderheide TP, Sigurdsson G, Pirrallo RG, Yannopoulos D, McKnite S, Briesen C, et al. Hyperventilation-induced hypotension dur- ing cardiopulmonary resuscitation. Circulation 2004;109(16):19601965.

2. McInnes AD, Sutton RM, Orioles A, Nishisaki A, Niles D, Abella BS, et. al. The first quantitative report of ventilation rate during in-hospital resuscitation of older children and adolescents. Resuscitation 2011;82(8):1025-1029.

3. Aufderheide TP, Lurie KG. Death by hyperventilation: a common and life-threatening problem during cardiopulmonary resuscitation. Crit Care Med 2004;32(9 Suppl):S345-S351.

4. Abella BS, Alvarado JP, Myklebust H, Edelson DP, Barry A, O'Hearn $\mathrm{N}$, et. al. Quality of cardiopulmonary resuscitation during in-hospital cardiac arrest. JAMA 2005;293(3):305-310.

5. Shin SD, Ahn KO, Song KJ, Park CB, Eui EJ. Out-of-hospital airway management and cardiac arrest outcomes: a propensity score matched analysis. Resuscitation 2012;83(3):313-319.

6. McMullan J, Gerecht R, Bonomo J, Robb R, McNally B, Donnelly J, et. Al. Airway management and out-of-hospital cardiac arrest outcome in the CARES registry. Resuscitation 2014;85(5):617-622.

7. Link MS, Berkow LC, Kudenchuk PJ, Halperin HR, Hess EP, Moitra VK, et al. Part 7: Adult Advanced Cardiovascular Life Support: 2015 American Heart Association Guidelines Update for Cardiopulmonary Resuscitation and Emergency Cardiovascular Care. Circulation 2015;132(18 Suppl 2):S444-S464.

8. Christenson J, Andrusiek D, Everson-Stewart S, Kudenchuk P, Hostler D, Powell J, et al. Chest compression fraction determines survival in patients with out-of-hospital ventricular fibrillation. Circulation 2009;120(13):1241-1247.

9. Meaney PA, Bobrow BJ, Mancini ME, Christenson J, de Caen AR, Bhanji F, et al. Cardiopulmonary resuscitation quality: [corrected] improving cardiac resuscitation outcomes both inside and outside the hospital: a consensus statement from the American Heart Association. Circulation 2013;128(4):417-435.

10 Bates D, Maechler M, Bolker B, Walker S. Fitting linear mixedeffects models using lme4. J Stat Softw 2015;67(1):1-48. doi: 10.18637/jss.v067.i01.

11 Kuznetsova A, Brockhoff PB, Christensen RHB. lmerTest: tests in linear mixed effects models: R package version 2.0-30. 2016. https:// CRAN.R-project.org/package $=$ lmerTest.

12 Geraci M. Linear quantile mixed models: the lqmm package for Laplace quantile regression. J Stat Softw 2014;57(13):1-29. doi: 10.18637/jss.v057.i13.

13 Wickham H. ggplot2: elegant graphics for data analysis. New York: Springer-Verlag; 2009.

14. Bergrath S, Rossaint R, Biermann H, Skorning M, Beckers SK, Rörtgen D, et al. Comparison of manually triggered ventilation and bag-valve-mask ventilation during cardiopulmonary resuscitation in a manikin model. Resuscitation 2012;83(4):488-493.

15. Busch CW, Qalanawi M, Kersten JF, Kalwa TJ, Scotti NA, Reip W, et al. Providers with limited experience perform better in advanced life support with assistance using an interactive device with an automated external defibrillator linked to a ventilator. J Emerg Med 2015;49(4):455-463.

16. Boussen S, Gainnier M, Michelet P. Evaluation of ventilators used during transport of critically ill patients: a bench study. Respir Care 2013;58(11):1911-1922.

17. Bordes J, Erwan d'Aranda, Savoie PH, Montcriol A, Goutorbe P, Kaiser E. $\mathrm{F}_{\mathrm{IO}_{2}}$ delivered by a turbine portable ventilator with an oxygen concentrator in an austere environment. J Emerg Med 2014;47(3):306-312. 